\title{
The Relationship between Learning Style and Quantitative/Qualitative Information Recall Performance
}

\author{
A.B.M ABDULLAH \\ JERRY LIGON \\ University of North Texas
}

\begin{abstract}
This study examined the ability of individuals to recall qualitative or quantitative information contained in reading passages. The subjects' scores on the Kolb Learning Style Inventory (KLSI) were analyzed to determine if an individual's learning style preference affected his/her information recall performance. Demographic variables, including age, sex, grade level, employment status and length, and ethnicity were also included in the analysis. One-way ANOVA analysis was conducted to test two proposed hypotheses. Results indicated that there was significant relationship between individuals learning styles and their ability to recall qualitative information. However, for the quantitative information the results were inconclusive. Regression analysis also indicated that there was a significant relationship between the type of information recalled and recall performance. In addition to information type (qualitative/quantitative), the abstract-to-concrete $A C-C E$ dimension score of the KLSI was also found to have significant impact on information recall performance.
\end{abstract}

\section{INTRODUCTION}

A comprehensive review of studies in cognitive psychology has indicated that people exhibit significant individual differences in cognitive processing styles that they adopt in information recalling, problem-solving and other similar decision-making activities (Robertson, 1985). Findings from both qualitative and quantitative research have indicated several consistent major dimensions of individual differences (Dunn, DeBello, Brennan, Krimsky, \& Murrain, 1981). Of these dimensions, learning style is a major contributor to the individual differences. 
Learning style refers to an individual's habitual or typical way of perceiving, remembering, thinking, problem solving, and information processing (Alport, 1976). According to Dunn (1984), learning style is "the way a person absorbs and retains information and/or skills." Kolb (1984) explains learning style as a preference, which develops and change over time. This idea supports the concept that a person's learning style is affected by individual's traits such as personality, cognitive styles, temperaments, sensory processes and age (Kolb, 1984; Fleming, 1995). Each learner has an individual learning style, which is thought to be an enduring, patterned, and preferred mode of learning (Sproles \& Sproles, 1990). However, as Griggs (1991) points out, it is important to recognize that learning styles are not related to intelligence, mental ability or actual learning performance. The best learning style for any individual is specific to the individual's cognitive abilities and the learning situation they are in (Logan \& Thomas, 2002).

Although the investigation of learning styles is a relatively new field of educational theory and research, having started in the late 1970s, in the last few decades, there has been considerable research in this area. Psychologists have extensively investigated learning style (Kolb, 1984; Dunn, 1984, Dunn \& Dunn 1978) with the central goal of characterizing how the mind operates when learning.

\section{Kolb's Learning Style Inventory (KLSI) \& Comprehension}

The Kolb LSI (1985) measures learning ability on two dimensions. The horizontal axis (see Figure 1) has active experimentation (AE) at one end and reflective observation (RO) on the opposite end. Learning in the active experimentation (AE) extreme takes place by doing, while learning in the reflective observation (RO) extreme takes place by watching and listening (observing). The vertical axis has concrete experience (CE) at one end and abstract conceptualization (AC) at the other end. Learning in concrete experience (CE) extreme involves learning from feelings, such as those drawn upon specific personal experiences. Learning in the abstract conceptualization (AC) extreme, on the other hand, relies on thinking and logical analysis.

The KLSI is a 12-item questionnaire in which subjects attempt to describe their learning preferences by completing a sentence with four different endings. The four choices are ranked from one to four. Scoring of the instrument results in two combination 
scores (AC-CE and AE-RO) that are plotted in quadrants to determine which of our four learning styles is dominant. The four learning styles are: Diverger (CE and $\mathrm{RO}$ ), Assimilitor ( $\mathrm{AC}$ and $\mathrm{RO}$ ), Converger (AC and $\mathrm{AE}$ ), and Accomodator (CE and $\mathrm{AE}$ ).

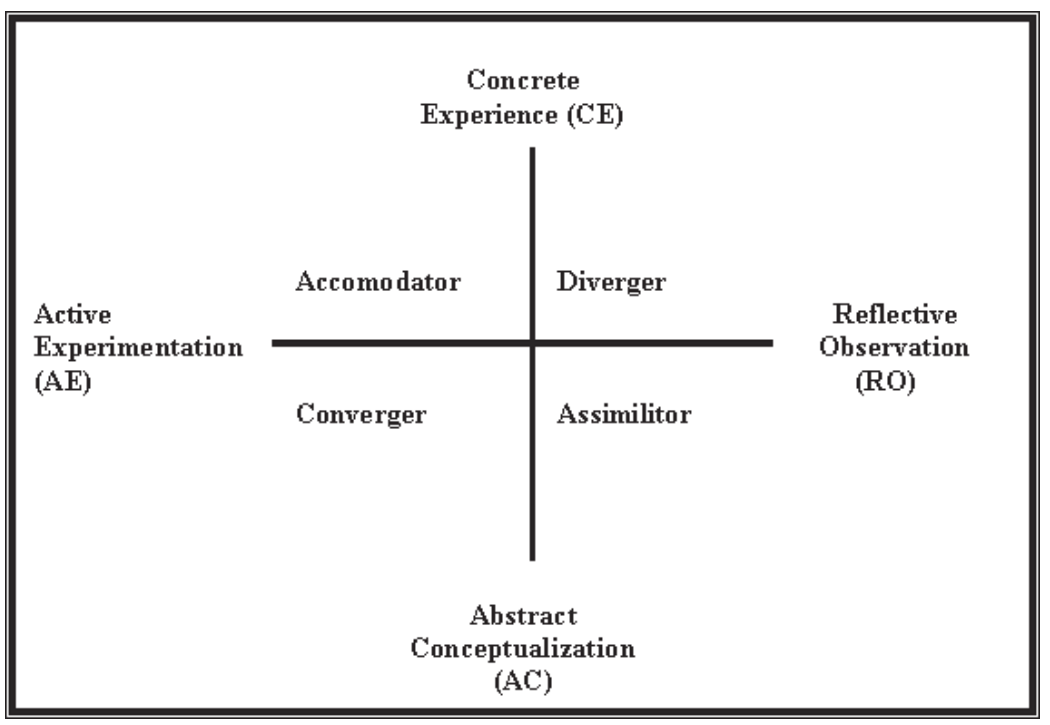

Figure 1. Kolb's learning style groups

Holley and Jenkins (1993) performed a study of accounting students to determine if learning style (as measured by Kolb's LSI) was related to performance on four different types of test question formats: multiple choice -theory, multiple choice-quantitative (problem solving), open-ended theory, and open-ended quantitative questions. The results show that for open-ended theory questions (the type of questions used in this study), the AC-CE measurement had significant impact on answer accuracy.

Bostrom, Olfman and Sein (1990) performed a four-part study of various types of end-user training and learning style. Comprehension was measured as the performance on a multiplechoice quiz given at the conclusion of the training sessions. In all three of the four studies that contained a comprehensive quiz, the abstracts (AC) outperformed the concretes (CE) on the comprehension measure with one study being statistically significant and two being marginally significant. 


\section{Quantitative/Qualitative Information Recall}

Information recall performance refers to how much information an individual can retain in his memory after being exposed to the information for a short-term. Quite a number of studies have been conducted for measuring an individual's information recall performance (Phaf \& Wolters, 1993). Many instruments used to measure aptitude and/or intelligence utilize the ability to recall numbers or digits as a sub-measure of overall aptitude or intellectual ability. Theses subtests entail the testing of short-term auditory recall whereby the subject repeats back to the examiner a series of digits in the order in which they were presented to the subjects. Such instruments include the Differential Ability Scales (DAS) (Elliot, 1990), The Wechsler Adult intelligence scale (Kaufman \& Lichtenberger, 1999), and the K-SNAP Number Recall (Horn \& Hofer, 1992). Testing the recall of numbers and digits has also been used as a distracter recall task, as in Phaf and Wolters (1993). No studies have been found, however, in which quantitative information was presented in a textual manner and where the focus is the recall of numbers presented within a reading passage.

The majority of research addressing the ability to recall information presented in written (reading) passages tests the ability to recall qualitative (textual) information. Some studies address the ability to recall specific words contained within the text (Meyer \& Poon, 2001), while others address the ability to recall concepts (ideas) contained within the text (Lowman \& Meyer, 1983). Many studies that focus on the effect of the organization of the reading material are based on ideas presented by Meyer (1975) and address the use of signaling and its related effect on information recall (Meyer \& Poon, 2001; Lowman \& Meyer, 1983; Lorch, 1989). Other studies address the length of the word or phonological properties in information recall (Tehan, Hendry \& Kochinski, 2001); though they present the material in the form of a list of words as opposed to contained within a reading passage. While certain inferences may be drawn from these studies, no studies can be found that differentiate between the ability to recall numeric versus non-numeric information presented in reading passages.

\section{Proposed Hypotheses}

The above discussion categorically makes it clear that an individual's learning style may have some impact on his/her ability to recall 
qualitative or quantitative information. To test this assertion and to find out what kind of information recall performance is mostly affected by individuals' learning styles, we have proposed the following null hypotheses.

$\mathrm{H}_{\mathrm{o} 1}$ : There is no significant relationship between an individual's preferred learning style and his/her ability to recall qualitative (textual/non-numeric) information.

$\mathrm{H}_{\mathrm{o} 2}$ : There is no significant relationship between an individual's preferred learning style and his/her ability to recall quantitative (numeric) information.

\section{METHOD}

Table 1. Demographics

\begin{tabular}{|c|c|c|c|c|}
\hline \multicolumn{5}{|c|}{ Qualitative Treatment } \\
\hline & Mean & Std. Dev 1 & Median $\mathbf{R}$ & Range \\
\hline Age & 24.00 & 5.09 & 23.00 & $18-43$ \\
\hline GPA & 2.67 & 0.98 & 3.00 & $0-3.75$ \\
\hline Level $(F R=1, S O=2, J R=3, S R=4, G R=5)$ & 3.38 & 0.86 & 3.00 & $1-5$ \\
\hline \multicolumn{5}{|c|}{ Qualitative Treatment } \\
\hline & Mean & n Std. Dev & v Median & n Range \\
\hline Age & 23.49 & 4.84 & 22.00 & $17-43$ \\
\hline GPA & 2.54 & 1.05 & 2.75 & $0-3.75$ \\
\hline Level $(F R=1, S O=2, J R=3, S R=4, G R=5)$ & 3.31 & 0.89 & 3.00 & $1-5$ \\
\hline \multicolumn{5}{|c|}{ All participants } \\
\hline & Mean & Std. Dev & Median & Range \\
\hline Age & 23.73 & 4.96 & 22.00 & $17-43$ \\
\hline GPA & 2.60 & 1.01 & 2.75 & $0-3.75$ \\
\hline Level ( $F R=1, S O=2, J R=3, S R=4, G R=5$ ) & 3.34 & 0.87 & 3.00 & $1-5$ \\
\hline
\end{tabular}




\section{Treatment Treatment Participants}

\begin{tabular}{llll}
\hline Employment & & & \\
$\quad$ Not employed (0) & $27.3 \%$ & $29.4 \%$ & $28.4 \%$ \\
Employed (1) & $72.7 \%$ & $70.6 \%$ & $71.6 \%$ \\
Average Length of & & & \\
Employment (months) & 34.80 & 31.80 & 33.25 \\
\hline Ethnicity & & & \\
Asian (0) & $13.0 \%$ & $20.0 \%$ & $16.7 \%$ \\
Black (1) & $10.4 \%$ & $12.9 \%$ & $11.7 \%$ \\
Hispanic (2) & $10.4 \%$ & $2.4 \%$ & $6.2 \%$ \\
White (3) & $62.3 \%$ & $56.5 \%$ & $59.3 \%$ \\
Other (4) & $3.9 \%$ & $8.2 \%$ & $6.2 \%$ \\
\hline Major & & & \\
Accounting (0) & $19.5 \%$ & $4.7 \%$ & $11.7 \%$ \\
BCIS/IT (1) & $26.0 \%$ & $35.3 \%$ & $30.9 \%$ \\
FINA/REAL (2) & $9.1 \%$ & $15.3 \%$ & $12.3 \%$ \\
LOGI/MKTG (3) & $20.8 \%$ & $15.3 \%$ & $17.9 \%$ \\
MGMT/POM (4) & $14.3 \%$ & $11.8 \%$ & $13.0 \%$ \\
Other (5) & $10.4 \%$ & $17.6 \%$ & $14.2 \%$ \\
\hline
\end{tabular}

\section{Participants}

The participants in this experiment were self-selecting volunteers and students in a moderately large university in the southwest United States. Each participant received nominal monetary compensation for participation and was eligible to receive a cash award for top performance. This study was part of a larger experiment conducted with other researchers. Of the 342 total participants, 326 completed the portions of the experiment related to this study. The subjects were randomly assigned to one of two treatments (quantitative recall or qualitative recall). No significant differences were found between group demographics (Table 1).

\section{Instruments}

Two separate passages of equal length were devised to assess recall performance. One passage was created to assess quantitative (numeric) recall performance (see Appendix-A), and another to assess qualitative (non-numeric or textual) recall performance (see 
Appendix-B). The dependent variable of recall performance is measured by the percentage of questions answered correctly. For the quantitative recall task, there were three questions and the answers to these questions contained four numbers. For each correct number, participants were awarded 0.25 points. For the qualitative recall task, again there were three questions and the perfect answers to these questions contained seven words. For each correct word the participants were awarded 0.14 points. Each reading passages were one paragraph (166 words) long and presented to the participants via computer screen (Appendix A \& B). The recall assessment questions were administered via penciland-paper.

To assess the participants learning styles, the KLSI-1985 was administered electronically near the end of the session (See Appendix-C). Learning style is measured as the participants resulting KLSI Learning Style category: Accomodator, Assimilitor, Converger, or Diverger. In addition, each individual's measure on Kolb's two dimensions (AC-CE and AE-RO) is utilized for regression analysis. A handout describing the various learning styles was provided at the end of the session so the participants could refer to it when results were provided at the end of the experiment period.

\section{Procedure}

The entire experiment was conducted in sessions of approximately one hour and thirty minutes in duration. A total of twenty- three sessions were conducted in a computer laboratory over an eleven day period. Each computer workstation was equipped with a 17inch colour monitor and had equivalent settings (i.e., resolution, etc.). The maximum number of participants in each session was 30. The participants were randomly assigned to one of 30 computers which contained one of the two recall performance tasks (see Appendix-D for experiment instructions).

Each participant was exposed to one of the two reading passages (either qualitative or quantitative recall task). 162 participants were exposed to the qualitative recall task (Appendix-A) and 164 participants were exposed to the quantitative recall task (Appendix $-\mathrm{B}$ ). The reading passage was presented to the participants approximately 30 minutes into the overall session and was preceded by a common set of instructions presented via the computer. Participants were instructed 
to read the passage and were told that they would be asked questions later in the session regarding the material presented to them. The passage was presented to the participant for two (2) minutes and timing was controlled via a timing mechanism programmed on the computer. The reading of the passage was followed by approximately five minutes of interruption tasks. Participants were then asked to complete the pencil-and-paper recall assessment questions.

\section{Results}

Table 2. One-way ANOVA results for qualitative information recall performance

\section{Groups Compared}

Accomodator vs. Assimilitor Accomodator vs. Converger

Diverger vs. Accomodator Assimilitor vs. Converger Assimilitor vs. Diverger Converger vs. Diverger

\section{F-Value P-Value F-Crit $\quad \mathbf{H}_{o 1}$}

\begin{tabular}{llll}
\hline 9.045 & $0.003^{*}$ & 3.932 & Reject \\
16.616 & $0.000^{*}$ & 3.930 & Reject \\
5.549 & $0.020^{*}$ & 3.951 & Reject \\
3.099 & 0.081 & 3.932 & Fto Reject \\
23.109 & $0.000^{*}$ & 3.935 & Reject \\
25.335 & $0.000^{*}$ & 3.986 & Reject \\
\hline
\end{tabular}

* Significance level 0.05 or $5 \%$

Table 3. One-way ANOVA results for quantitative information recall performance

\section{Groups Compared}

Accomodator vs. Assimilitor

Accomodator vs. Converger

Diverger vs. Accomodator

Assimilitor vs. Converger

Assimilitor vs. Diverger

Converger vs. Diverger

F-Value P-Value F-Crit $\quad \mathbf{H}_{\text {o2 }}$

\begin{tabular}{llll}
\hline 7.103 & $0.008^{*}$ & 3.958 & Reject \\
1.293 & 0.251 & 3.986 & Fto Reject \\
1.330 & 0.512 & 3.951 & Fto Reject \\
21.121 & $0.000^{*}$ & 3.932 & Reject \\
23.109 & $0.002^{*}$ & 3.937 & Reject \\
0.0006 & 0.982 & 3.954 & F to Reject
\end{tabular}

Note: $*$ Significance level 0.05 or $5 \%$; Fto $=$ Fail to

One-way ANOVA analysis was conducted based on the collected data to test two proposed hypotheses. ANOVA results for qualitative and quantitative information recall are presented in Table 2 and Table 3 respectively. 
Since five out of six ANOVA (Table 2) conducted on qualitative information recall performance indicate that the null hypothesis $\left(\mathrm{H}_{\mathrm{O} 1)}\right.$ can be rejected, we can conclude that there is indication of significant difference in terms of qualitative information recall performance based on individuals learning styles. On the other hand, based on the ANOVA results in Table 3, we are unable to draw any definitive conclusion about the validity/rejection of $\mathrm{Ho}_{2}$ : only three out of six results indicate significant differences (reject the null hypothesis) in quantitative information recall performances based on learning styles.

For the regression analysis, the dependent variable of interest in this study was the information recall performance as measured by the percentage of items successfully recalled (see methodology section for calculation procedure). The primary independent variables of interest are the type of information recalled (qualitative/quantitative) and the Kolb LSI dimension metric scores (AC-CE and AE-RO). The type of information recalled utilized a dummy coded variable (Qualitative $=1$, Quantitative $=0$ ). Also included in the analysis, as possible demographic explanatory variables, were age, gender (Male $=0$, Female $=1)$, grade level $(\mathrm{FR}=1, \mathrm{SO}=2, \mathrm{JR}=3, \mathrm{SR}=4, \mathrm{GR}=5)$, selfreported GPA, employment status (Not employed $=0$, Employed $=$ 1), employment length, and ethnicity $($ Asian $=0$, Black $=1$, Hispanic $=$ 2 , White $=3$, Other $=4$ ).

The initial regression model included all independent variables of primary interest to the study, as well as, all demographic variables. While the overall model was found to be significant with an F-value of $4.174(\mathrm{p}<.00)$, none of the demographic variables were found to be significant. The variable indicating the type of information recalled was found to be significant with a t-value of $5.276(\mathrm{p}<.00)$. The LSI dimension metric for abstract-to-concrete (AC-CE) was also significant with a t-value of $2.038(\mathrm{p}<.05)$. The LSI dimension metric for activeto-reflective (AE-RO) was not found to be significant in the overall model.

A second regression analysis was performed with only the independent variables of interest in this study (without the demographic variables). Similar results were found using this model. The type of information recall was again found to be significant with a t-value of $5.730(\mathrm{p}<.00)$. The abstract-to-concrete (AC-CE) dimension metric was also found to be significant with a t-value of $2.152(\mathrm{p}<.05)$. This 
finding is consistent with previous findings that the AC-CE dimension has a significant effect on a student's ability to answer textual questions (Holley \& Jenkins, 1993). The active-to-reflective (AE-RO) dimension metric was not found to be significant in this model. Tables 4 and 5 summarise the results of the regression analyses.

Table 4. Summary of regression results

\begin{tabular}{lcccc}
\hline Dependent Variable & $\mathbf{R}^{2}$ & Adj. $\mathbf{R}^{2}$ & F-statistic & $\begin{array}{c}\text { Significance } \\
\text { Level }\end{array}$ \\
\cline { 2 - 5 } & 0.632 & 0.598 & 4.174 & 0.000 \\
$\begin{array}{l}\text { Recall performance } \\
\left(1^{\text {st }} \text { regression }\right)\end{array}$ & 0.576 & 0.573 & 4.061 & 0.000 \\
$\begin{array}{l}\text { Recall performance } \\
\left(2^{\text {nd }} \text { regression }\right)\end{array}$ & & & & \\
\hline
\end{tabular}

Table 5. Summary of regression results

Dependent Variable Significant Coefficients $(P<0.05)$

\begin{tabular}{|c|c|c|c|c|c|c|c|c|}
\hline & Q1* & Q2* & Q3* & Q4* & Q5* & Q6* & Q7* & Q8* \\
\hline $\begin{array}{l}\text { Recall performance } \\
\left(1^{\text {st }} \text { regression }\right)\end{array}$ & 0.082 & 0.031 & - & - & - & - & - & - \\
\hline $\begin{array}{l}\text { Recall performance } \\
\left(2^{\text {nd }} \text { regression }\right)\end{array}$ & 0.083 & 0.029 & - & - & - & - & - & - \\
\hline
\end{tabular}

${ }^{*}$ Q1: Type of information recall (qualitative/quantitative); *Q2: Kolb LSI dimension metric score AC-CE; ${ }^{*} \mathrm{Q} 3$ : Kolb LSI dimension metric score AE -RO; ${ }^{*}$ 4: Age; ${ }^{*}$ Q5: Gender; ${ }^{*} \mathrm{Q} 6:$ Grade; ${ }^{*}$ Q7: Self-reported GPA; $*$ Q8: Employment Status

\section{Discussion}

ANOVA results (Tables $2 \& 3$ ) indicate that different learning groups vary significantly in terms of qualitative information recall performance based on their learning styles. The data show that Convergers (75\%) and Assimilitors (71\%) had significantly higher average recall performance on qualitative information than Divergers (58\%) and Accomodators (64\%). This particular finding signifies that Convergers and Assimilitors will outperform Accomodators and Divergers in a test/work environment which requires recalling qualitative information. 
On the other hand, the results were inconclusive for the quantitative information recall performance. All the learning groups had extremely close average recall performance scores on quantitative information (Assimilitors 42\%, Convergers 35\%, Divergers 42\%, Accomodators $38 \%$ ). This leads us to conclude that an individual's ability to recall quantitative information is not attributable to his/her preferred learning style as measured by KLSI.

In addition to the type of information recalled, regression analysis found that AC-CE dimension score of the KLSI has significant influence on an individual's information recall performance for both qualitative and quantitative information. Individuals with higher AC-CE scores will perform better than other individuals in recalling any type of information. This helps to lend further support that individuals whose preference is for abstract conceptualization, as opposed to concrete experimentation, are better able to perform on tasks which requires some type of information recall. This finding is also consistent with previous research findings that individuals with a positive AC-CE LSI dimension score perform better on qualitative information recall tasks. The regression analysis did not find any significant relationship between the AE-RO LSI dimension score and the recall performance, meaning Divergers and Assimilitors are no better performers than Accommodators and Convergers in general recall tasks.

The findings of this study can help academic or career advisors in advising their students based on their learning style preferences. For example, since Convergers and Assimilitors can perform better than Divergers and Accomodators in recalling qualitative information they might do well in history or political science classes that require extensive memorization of certain type of information. At the same time, students with higher AC-CE LSI dimension scores are more likely to outperform their cohorts in these courses because of their higher ability to recall quantitative and/or qualitative information.

The weaknesses of the study are primarily in instrument design. The reading passages utilized should be further validated. More consistent and useful results may have been obtained had a single reading passage been devised that could have been utilized by both study groups. One option of this variant would be a reading passage where differing target items were intermingled within the text. A second option would be to have two versions of the reading passage where one contained the number word within the text and the other the numeric equivalent. 


\section{REFERENCES}

Allport, A. (1976). Personality: A psychological interpretation. New York: Holt \& Co.

Bostrom, R. P., Olfman, L., \& Sein, M. K. (1990). The importance of learning style in end-user training. MIS Quarterly, 1, 101-119.

Dunn, R., DeBello, T., Brennan, P., Krimsky, J., \& Murrain, P. (1981). Learning style researchers define differences differently. Educational Leadership, 38, 327-374.

Dunn, R. (1984). Learning Style: State of the Science. Theory into Practice, 23, 10-19.

Dunn, R. \& Dunn, K. (1978). Teaching students through their individual learning styles: A Practical Approach. VA: Reston Publishing Company, Inc.

Elliot, C.D. (1990). Differential Ability Scales: Introductory and technical handbook. TX: Psychological Corporation.

Fleming, N.D. (1995). I'm different; not dumb. Modes of presentation (VARK) in the tertiary classroom. In Zelmer, A., (Ed.) Research and development in higher education, Proceedings of the 1995 Annual Conference of the Higher Education and Research Development Society of Australasia (HERDSA), HERDSA, 308-313.

Griggs, S.A. (1991). Learning styles counseling. ANN Arbor: Clearinghouse on Counseling and Personnel Services.

Holley, J.H., \& Jenkins, E.K. (1993). The relationship between student learning style and performance on various test question formats. Journal of Education for Business, 2, 301-308.

Horn, J.L., \& Hofer, S.M. (1992). Major ability and development in the adult period. In R.J. Sternberg \& C.A. Berg (Eds.), Intellectual Development (pp. 44-99). Boston, MA: Cambridge University Press.

Kaufman, A.S., \& Lichtenberger, E.O. (1999). Essentials of WAISIII Assessment (Essentials of Psychological Assessment Series). New York, NY: John Wiley \& Sons, Inc.

Kolb, D.A. (1984). Experiential learning: Experience as the source of learning and development. Englewood Cliffs, NJ: Prentice-Hall.

Kolb, D.A. (1985). Learning Style Inventory: Self-scoring inventory and interpretation booklet. Boston: McBer \& Company.

Logan, K. \& Thomas, P. (2002). Learning styles in distance education students learning to program. In $14^{\text {th }}$ Workshop of the Psychology of Programming Interest Group, Brunel University, 29-44. 
Lowman, N.L., \& Meyer, R.E. (1983). Signaling techniques that increase the understandability of expository prose. Journal of Educational Psychology, 75, 402-412.

Lorch, R.F. Jr. (1989). Text signaling devices and their effects on reading and memory process. Educational Psychology Review, 1, 209-234.

Meyer, B. J. F. (1975). The organization of prose and its effect on memory. Amsterdam: North Holland Pub. Co.

Meyer, B. J. F., \& Poon, L. W. (2001). Effects of structure strategy and signaling on recall of text. Journal of Educational Psychology, 93, 141-159.

Phaf, R. H., \& Walters, G. (1993). Attentional Shifts in maintenance rehearsal. American Journal of Psychology, 106, 353-382.

Robertson, I. T. (1985). Human information-processing strategies and style. Behavior and Information Technology, 4, 19-29.

Sproles, E. K., \& Sproles, G. B. (1990). Consumer decision-making styles as a function of individual learning styles. Journal of Consumer Affairs, 24, 134-147.

Tehan, G., Hendry, L., \& Kocinski, D. (2001). Word length and phonological similarity effects in simple, complex, and delayed serial recall tasks: implications for working memory. Memory, 9, 333-348. 


\section{APPENDIX A (Quantitative Recall Task)}

\section{Reading Passage (166 words):}

Dow Jones Industrial Average (DJIA) had marked a record low closing index of 10010 in May 13, 2000. However, most of the investors are expecting that the market will follow a bullish trend from the beginning of June. Most of the market analysts from the top five investment firms are hopeful that the market will go up by $9.975 \%$ to $11.275 \%$ in the next three months. If the market really meets the analysts' expectations index will again hit 11000 level very soon. Some market researchers are so optimistic that they are expecting a market index 36000 in next 7 years. The question is even if the market is able to hit that target will that be able to sustain that for a long time or will there be a repetition of black Monday of 1987 when the market index went down by $25 \%$ in a single trading day. Probably, it is not a good idea to inflate the index without building adequate fundamentals for that.

\section{Assessment Questions:}

1 What was the Dow Jones Index in May 13, 2000?

2 The analysts were expecting that the market index would go up by what percentage (Write the range)?

3 The market index was expected to hit what level in June 2000?

\section{APPENDIX B (Qualitative Recall Task)}

\section{Reading Passage (166 words):}

Anatolia news agency reported that Vice-president Al Gore went to Ankara, Turkey to attend a seminar on "The future of NATO (North Atlantic Treaty Organization)". NATO was formed during the time of cold war to provide national security to the member countries from any kind of attacks from the former Soviet Union. Most of the NATO members are western European countries with democratic government policy. With the collapse of the former U.S.S.R (Union of Soviet Socialist Republic) and rapid 
changes in the political environment of Eastern European countries NATO has expanded its membership to 19. Some of the NATO member countries are: Belgium, Czech Republic, France, Germany, Greece, Hungry, Italy, Luxemburg, Netherlands, and Turkey. Initially, NATO started with 13 member countries. Most of the members were western European countries since they felt the most threat from the Warsaw lead by former Soviet Union. Threat was really coming from the arrogant autocrats who were controlling and spreading the communist ideology in most of the Eastern European countries.

\section{Assessment Questions:}

1 List five Names of NATO Member Countries mentioned in the above paragraph.

2 NATO was formed to serve what purpose?

3 What is the name of the news agency that reported the news?

\section{APPENDIX C (Kolb's Learning-Style Inventory)}

Below you will be asked to complete 12 sentences. Each has four endings. Rank the endings for each sentence according to how well you think each one fits how you would go about learning something. Try to recall some recent situation where you had to learn something new, perhaps in your job. Then, using the spaces provided, rank a " 1 " for the sentence ending that describes how you learn best, down to a " 4 " for the sentence ending that seems least like the way you learn. Be sure to rank all endings for each sentence unit. Please do not make ties. Make sure, add up values for each row is exactly 10 . Remember, $1=$ most like you, $2=$ second most like you, $3=$ third most like you and $4=$ least like you 
Example of completed sentence set:

\begin{tabular}{|c|c|c|c|c|c|c|c|c|}
\hline o. When I leam: & I am happy & 2 & lam fast & 1 & lam logical & 3 & I am careful & 4 \\
\hline 1. When I learn: & $\begin{array}{l}\text { l like to deal with my } \\
\text { feolings }\end{array}$ & & $\begin{array}{l}\text { I like to watch and } \\
\text { listen }\end{array}$ & & $\begin{array}{l}\text { I like to think about } \\
\text { idoas }\end{array}$ & & $\begin{array}{l}\text { I like to be doing } \\
\text { things }\end{array}$ & \\
\hline $\begin{array}{l}\text { 2. I learn best } \\
\text { when: }\end{array}$ & $\begin{array}{l}\text { I trust my hunches and } \\
\text { feelings }\end{array}$ & & $\begin{array}{l}\text { I isten and watch } \\
\text { carefully }\end{array}$ & & $\begin{array}{l}\text { I rely on logical } \\
\text { thinkang }\end{array}$ & & $\begin{array}{l}\text { I work hard to } \\
\text { get things done }\end{array}$ & \\
\hline $\begin{array}{l}\text { 3. When I am } \\
\text { learning }\end{array}$ & $\begin{array}{l}\text { I have strong feelings } \\
\text { and reactions }\end{array}$ & & $\begin{array}{l}\text { I am quiet and } \\
\text { reserved }\end{array}$ & & $\begin{array}{l}\text { I tend to reason } \\
\text { things out }\end{array}$ & & $\begin{array}{l}\text { I am responsible } \\
\text { about things }\end{array}$ & \\
\hline 4. I learn by. & feeling & & watching & & thinking & & doing & \\
\hline 5. When I learn: & I am open to newideas & & $\begin{array}{l}\text { Illook at all sides of } \\
\text { issues }\end{array}$ & & $\begin{array}{l}1 \text { like to analyze } \\
\text { things, break them } \\
\text { down into their } \\
\text { parts }\end{array}$ & & $\begin{array}{l}1 \text { like to try } \\
\text { things out }\end{array}$ & \\
\hline $\begin{array}{l}\text { 6. When I am } \\
\text { learning }\end{array}$ & I am an intuitive person & & $\begin{array}{l}\text { I am an observing } \\
\text { person }\end{array}$ & & $\begin{array}{l}\text { I am a logical } \\
\text { person }\end{array}$ & & $\begin{array}{l}\text { I am an active } \\
\text { person }\end{array}$ & \\
\hline $\begin{array}{l}7.1 \text { learn best } \\
\text { from: }\end{array}$ & personal relationships & & observation & & rational theories & & $\begin{array}{l}\text { a chance to try } \\
\text { out and practice }\end{array}$ & \\
\hline 8. When I learn: & $\begin{array}{l}\text { I feel personally } \\
\text { involved in things }\end{array}$ & & $\begin{array}{l}\text { I take my time before } \\
\text { acting }\end{array}$ & & $\begin{array}{l}\text { I like ideas and } \\
\text { theories }\end{array}$ & & $\begin{array}{l}1 \text { like to see } \\
\text { results from my } \\
\text { work }\end{array}$ & \\
\hline $\begin{array}{l}9.1 \text { learn best } \\
\text { when: }\end{array}$ & I rely on my feelings & & $\begin{array}{l}\text { I rely on my } \\
\text { observations }\end{array}$ & & I rely on my ideas & & $\begin{array}{l}1 \text { can try things } \\
\text { out for myself }\end{array}$ & \\
\hline $\begin{array}{l}\text { 10. When I am } \\
\text { learning }\end{array}$ & $\begin{array}{l}\text { I am an accepting } \\
\text { person }\end{array}$ & & $\begin{array}{l}\text { I am a reserved } \\
\text { person }\end{array}$ & & $\begin{array}{l}\text { I am a rational } \\
\text { person }\end{array}$ & & $\begin{array}{l}\text { Iam a } \\
\text { responsible } \\
\text { Derson }\end{array}$ & \\
\hline 11. When I leam: & I get involved & & I like to observe & & I evaluate things & & $\begin{array}{l}\text { I like to be } \\
\text { active }\end{array}$ & \\
\hline $\begin{array}{l}\text { 12. I learn best } \\
\text { When: }\end{array}$ & $\begin{array}{l}\text { I am receptive an open- } \\
\text { minded }\end{array}$ & & I am careful & & I analyze things & & I am practical & \\
\hline
\end{tabular}

\section{APPENDIX D (Experiment Instructions)}

Thank you for agreeing to participate. Before you begin, there are a few preliminary things that should be taken care of.

You will be receiving a series of instructions, both orally and in writing, during this experiment. It is important that you follow the instructions precisely. Failure to follow the instructions will likely invalidate your answers and result in your disqualification, and possibly the disqualification others' who may participate in this experiment at a later date. It is important that you do not discuss the details of your participation in this experiment until it is concluded (in approximately 1 week).

Each work station is equipped with a headset. Shortly, you will be instructed to place the headset on your head. You will be listening to music during Part I of the experiment. However, the headset may have been worn by others in a previous session of this experiment. If you would like a disinfectant wipe, please raise your hand and we will supply you with one before you begin. 
Before you begin, make sure that you have all of the initial materials. Please check to make sure you have the following:

- [Web Assessment Questionnaire]

- $3 \frac{1}{2}$ inch diskette

- two $3 \times 5$ cards bearing your participant number

- pen or pencil

Please raise your hand if you do not possess all of these items.

Let's begin.

This part of the experiment is not timed and you may proceed at your own pace. There are no right or wrong answers to any questions in this section, but the information you provide will assist us in interpreting the results of the experiment. You must complete all parts and do them in the order listed.

If you have any questions about any part of this section or need help in completing the instruments, please raise your hand and we will assist you.

\section{Step 1: Recording data about you}

The first step in this part of the experiment is to complete a series of demographic questions. You should activate the link below to complete this segment. Once you have completed your entries, press the "Accept Data" button on the bottom of the screen. If you have completed the necessary entries, your screen will not change and the data will be recorded on the disk in drive A. Once the disk drive light goes out, you should press the "Back" button to return to this page and continue to step 2.

If there are problems with your entries, you will see a "Demographic Data Confirmation" screen that identifies problems with the data. Once you have inspected the problems with your data, press the "Back" button to return to the data entry screen. Make the necessary corrections and press the "Accept Data" button on the bottom of the screen (as described above). 


\section{Step 2: What is your Learning Style}

The next step is to complete the Learning Style Inventory. You should activate the link below to complete this segment. Carefully read the instructions at the top of the form and complete the instrument. Once you have completed your entries, press the "Accept Form" button on the bottom of the screen. If you have successfully completed the form, your screen will not change and the data will be recorded on the disk in drive A. Once the disk drive light goes out, you should press the "Back" button to return to this page and continue to step 3 .

If there are problems with your entries, you will see a "LSI Data Confirmation" screen that identifies problems that exist on a question-by-question basis. Once you have inspected the problems with your answers, press the "Back" button to return to the data entry screen. Make the necessary corrections and press the "Accept Form" button on the bottom of the screen (as described above). This process may be repeated as many times as necessary to satisfactorily complete the instrument. 